\title{
Writing Apprehension and Academic Achievement Among Undergraduate Honors Students
}

\author{
Carl H. Boening and Lara Anderson Miller
}

\begin{abstract}
College students face many challenges upon their arrival to campus. One growing concern is the writing skill level of students, particularly when issues of technologicallymediated writing are considered. This study examines writing apprehension among honors students at one university. Results indicated that moderate levels of writing apprehension do exist among these honors students, and that some relationship between fear of writing and poor academic performance does exist.
\end{abstract}

The process of writing has grown in importance to be a key element for student success in college, particularly as it relates to interaction with different technologies (Neff, Bourret, \& Nelson, 1992). Indeed, reliance on written products by students has strong historical roots in higher education, but have only recently become even more important with the advent of the technology dependent campus. The pervasive nature of technology has grown to the point where students interact daily with a variety of technologies: the internet, bank machines, computerized registration, library searches, writing papers, journaling, etc.

Regardless of interaction with technology, the fundamental process of communication through written work remains consistent. The process of writing and the written product for students is paramount to their learning, and as a result, the understanding of the impact of the fear or anxiety related to writing is a necessity.

The concept of writing apprehension is inclusive of anxiety, and relates to the idea that some individuals are more comfortable and may enjoy the writing process while others do not. Larson (1985) contended that writing apprehension (WA) may be related to the arousal of certain emotions, particularly when written products are to be evaluated. Daly and Wilson (1983) considered WA a continuous person dimension, and have reported apprehension as related to academic success, occupational decisions, self-esteem, and personality behaviors.

Many colleges and university leaders have recognized the difficulty of sustaining academic performances throughout a students college career, and have responded with programs such as honors societies, classes, and dormitories to aid outstanding students. The current study was designed to examine levels of writing apprehension among these academically successful students and how writing apprehension on the contemporary college campus relates to academic achievement.

Carl H. Boening, Ed.D. is the Library Systems Officer of the Brooks-Cork Library at Shelton State Community College in Tuscaloosa, AL. Lara Anderson Miller is an ESL teacher in San Jose, CA. An earlier version of their paper was presented at the Annual Alabama Higher Education Research Seminar in Tuscaloosa, AL. 


\section{Rationale for the Study}

The concept of fear or anxiety related to the communication process was originally studied and described as the term "stage fright" (Clevenger, 1955), and has subsequently been widely studied within the realm of higher education (Miller, Edmunds, \& Newman, 1996). Communication apprehension relates to an individual's fear or reticence toward oral communication, and writing apprehension has been viewed as a tenet of the broader concept of communication apprehension.

Bloom (1980) described WA as a behavioral trait, as opposed to a state or trait descriptor of an individual, and Daly (1979) defined writing apprehension as:

(A) $n$ individual difference characterized by a general avoidance of writing and situations perceived by the individual to potentially require some amount of writing accompanied by the potential for evaluation of that writing (p. 37).

Writing apprehension relates directly to the anxiety associated with the writing process, inclusive of the conceptual as well as physical aspects of writing. Further, WA includes the fear of the evaluation of the written products (Daly, 1979). The anxiety can be severe to the level of debilitation, and has been directly linked to self-esteem and self-image (Minot \& Gamble, 1991), lower standardized test scores (Faigley, Witte, \& Daly, 1981), academic and occupational choices (Daly \& Shamo, 1976), and poor academic achievement in the classroom (Daly, 1979). College students with higher WA levels have been additionally reported to avoid courses which require writing, namely composition classes (Buley- Meissner, 1989).

To compensate for the difficulties arising from higher WA, researchers have advocated a number of strategies to work with and within students to overcome their fears and anxieties. Utilizing the teacher as team -partner in the writing process (Mikkelsen, 1984), use of writing partners and peer evaluation (Gillis, 1994), demonstrations (Neilsen, 1986), and broad environmental and process focused activities (Miller, 1995) have all been advocated to deal with student WA.

Contemporary college students are difficult to singularly describe, and there are certainly no all-effective strategies for addressing WA. Many colleges and university leaders, however, have developed remedial and special coursework to address the special needs of at-risk students. Largely ignored, however, are the students who have excelled in the classroom, and who often participate in some form of honors program. These individuals are typically viewed in the literature as successful, and have been often dismissed for distress or difficulty in completing or succeeding in the classroom.

Recognizing the unique challenges and dearth in the literature regarding academically successful students, the current study was tailored to describe their WA, as well as to examine the possible relationship between successful students academic achievement and WA. This issue is of vital importance for reasons of understanding academic success as well as suggesting the need to study the writing process as college campuses become increasingly technologically based. 


\section{Methods}

A study specific survey instrument was developed for the current investigation. The instrument consisted of 22 questions, with the first two questions asking the respondent to indicate years enrolled at the University of Alabama and current cumulative (overall) grade point average (on a four- point scale with 4.0 equivalent to an A average). The next 20 questions consisted of Daly and Miller's Writing Apprehension Test (WAT) which had previously been developed to measure apprehension or anxiety and fear of writing (Richmond \& McCroskey, 1989).

The WAT has been used often in English courses and programs (Richmond \& McCroskey, 1989), and has been utilized in work with faculty development (Miller, Edmunds, \& Newman, 1996) programs and in vocational education studies (Miller, 1995). The WAT is comprised of 20 items where respondents are asked to respond or provide their perceptions of each statement. The results of the instrument scoring is a score between 20 and 100, where scores below 45 indicate low levels of writing apprehension, 45 to 75 represent moderate or normal writing apprehension, and scores over 75 indicate a high level of writing apprehension. The instrument has been reported to have a moderate correlation with oral communication apprehension (Richmond \& McCroskey, 1989), and has had high levels of internal reliability consistently reported (Miller, 1995).

The sample for the current study consisted of 91 undergraduate college students living in a men's honor's dormitory at the University of Alabama. The instrument was distributed at a residence hall meeting.

\section{Results}

A total of 75 usable responses were obtained from undergraduate honor program students, representing an $83 \%$ return rate to the survey distribution. Of the 75 respondents, $85 \%$ self-reported their cumulative grade point average to be between 3.00 and 4.00 , and $15 \%$ reported a grade point average between 2.50 and 2.99 . No self-reported grade point averages were below 2.50 .

The overall group mean score for the respondents on the Writing Apprehension Test was 50 with a range of 29 for the lowest WAT score to 65 for the highest WAT score, indicating moderate writing apprehension for the group (instrument provides a range of 20 to 100, where 45 or lower indicates low writing apprehension and 75 or higher indicates high writing apprehension). The Pearson Product Moment Correlation was conducted (alpha .05) on the respondent data, combining self-reported grade point averages and WAT scores. The resulting Pearson $r=-.4662$, thus indicating a statistically moderate to low negative correlation, where increased writing apprehension correlated with lower grade point averages.

\section{Discussion}

The current discussion was designed to first ascertain the levels of writing 
apprehension among honors students, and secondly to attempt to identify this fear of writing with academic achievement. Responses to the WAT indicated moderate levels of apprehension to writing, falling well within the midrange of the instrument, thus providing a perception that these students who have excelled in the classroom and on campus are capable writers. Secondly, the results of the correlation analysis furthers the argument that some relationship between fear of writing and poorer academic performances does exist.

These findings combine to suggest first a growing need to examine the impact of technology on the academic cirriculum, and second, that writing performance and the mental process of writing may prove to be an issue important to both basic and advanced writers. The challenge to personnel in student affairs and those working with academic success centers, then, is to incorporate mechanisms for understanding the apprehensive nature of some writers, and tailoring some form of program to reduce the fear of the writing process. These strategies, as identified in the literature, may range from informal writing episodes designed to encourage writing without the fear of evaluation to teaming successful and high WA writers to collaborate.

In addition to dealing with students once they are involved in the collegiate experience, early warning signs of WA among first year students may help to reduce non-success and early-withdraw from college among students. Conceptually, greater success in the classroom through lowered WA may indeed prove to be a valuable factor in better understanding retention and at-risk students.

Suggested in the literature review but not addressed in the Daly and Miller WAT is that of the impact of technology on WA and academic success. Although technology has influenced the entire college campus, and in some instances has become the campus as in the case of the proposed "Virtual University," relatively little is known about how this access and process of information impacts student learning. Advances and the now common use of personal computers in word processing has introduced temporary writing, that is, the development and production of written work which can be deleted and modified through software applications; there is a lack of permanence on the computer screen as compared to typed or hand-written pages of writing. This temporary writing may serve to help lower feelings of reticence toward the writing process, but may in turn introduce technology apprehension.

Findings also have direct bearing on transitional programs for first-year and transfer students. First, academic success skills and attention is generally provided in transitional programs, but, they typically do not provide the range of developmental offerings needed by students. The consideration is not so much about remediation, but rather, reducing fears and concerns about academic performance. As noted in other works and the CAS Standards for New Student Orientation, a general expectation of orientation and transitional programs is the conveying of institutional expectations to new students. A second dimension to this writing apprehension and academic achievement is the need for peer support and other forms of mentoring. If students are provided the opportunity for non-judgmental support that creates an environment of improved performance based on self-direction, results may be seen in areas that students have direct control over, such as their performance related fears and apprehensions. The most important consideration for 
transitional professionals, though, is in the recognition that fears and apprehensions related to writing and other forms of communication do exist, and finding communication levels, intensities, and appropriate channels are necessary to help students succeed.

The current investigation provides a foundation for the continued study of the academic success of college students. This foundation is replete with environmental and psychological factors, but can only be effective in advancing the study of academic success in college if it accepts the continually changing nature of higher education. The call then is for those studying higher education to join with practitioners in student affairs as well as those in campus planning to chart the course for a fuller and broader study and understanding of the college student.

\section{References}

Bloom, L. Z. (March 1980). The composing processes of anxious and non-anxious writers: A naturalistic study. Conference on College Composition and Communication, Washington.

Buley-Meissner, M. L. (1989). “Am I really that bad?”: Writing apprehension and basic writers. Journal of Basic Writing, 8 (2), 3-20.

Clevenger, T. (1955). A definition of stage fright. Central States Speech Journal, 7, 26-30.

Daly, J. (1979). Writing apprehension in the classroom: Teacher role expectancies of the apprehension writer. Research in the Teaching of English, 13, 37-44.

Daly, J. A., \& Wilson, D. A. (1983). Writing apprehension, self-esteem, and personality. Research in the Teaching of English, 17, 327-341.

Faigley, L., Witte, S., \& Daly, J. (1981). The role of writing apprehension in writing performance and competence. Journal of Educational Research, 75, 16-21.

Gillis, C. (1994). Writing partners: Expanding audiences for student writing. English Journal, 83 (3), 64-74.

Larson, R. (1985). Emotional scenarios in the writing process: An examination of young writers' affective experiences. In M. Rose (Ed.) When a Writer Writes. NY: Guilford.

Mikkelsen, N. (1984). Teacher as partner in the writing process. Language Arts, 61 (7), 704-711.

Miller, M. T. (1995). Strategies for reducing writing apprehension among pre-service teachers. Speech and Theater Association of Missouri Journal, 25, 33-41.

Miller, M., Edmunds, N., \& Newman, R. (1996). Vocational and technical education faculty perceptions toward writing apprehension. Journal of Technology Studies, 22 (1), 45-48.

Minot, W. S., \& Gamble, K. R. (1991). Self-esteem and writing apprehension of basic writers: Conflicting evidence. Journal of Basic Writing, 10 (2), 116-124.

Neff, G., Bourret, R., \& Nelson, R. (1992). Computer-aided writing: An emerging field. The Journal, 20 (1), 73-79. 
Neilsen, A. R. (1986). Knowing by doing: An active approach to writing inservice. Journal of Reading, 29 (8), 724-728.

Richmond, V. P., \& McCroskey, J. C. (1989). Communication apprehension, avoidance, and effectiveness (2nd. Ed.). Scottsdale, AZ: Corsuch Scarisbrick. 